\title{
Pemberdayaan Masjid dalam Kehidupan Sosial-Agama Masyarakat Desa Tanjungtani Kecamatan Prambon Kabupaten Nganjuk
}

\author{
Imam Basthomi \\ UIN Sunan Kalijaga Yogyakarta \\ E-mail:basthomi04@gmail.com
}

\begin{abstract}
Mosque is a place of worship for Muslims. Long time ago mosque became central activities of Muslims. In modern era, mosque has experienced a decline function. It's necessary to optimize the function and role of the mosque so that it's not only used to as place for prayer. Tanjungtani village is located in Prambon district Nganjuk Regency East Java. That village well known has many Pondok Pesantren however in there still have many abangan people. That phonemon has changed when Baitul Makmur Mosque was built. Aim of this article is give description about empowerement of Baitul Makmur Mosque in social-religious life of Tanjungtani people. This research includes qualitative research using historical and social approaches. The methods to collect data is interview, literature review, and observation. Talcott Parsons' functional theory is used by researchers as an analytical tool. The results of this research show mosque empowerement is very important for social life and it's can help to optimize the function and role of mosque towards local society needs.
\end{abstract}

Keywords: Mosque, Empowerment, and Function

Abstrak. Masjid merupakan tempat peribadatan umat Islam. Pada zaman dabulu masjid menjadi pusat kegiatan umat Islam. Pada masa modern masjid mengalami penurunan dan penyempitan fungsi. Perlu adanya optimalisasi fungsi dan peran masjid agar masjid tidak hanya sebagai tempat untuk menjalankan salat saja. Desa Tanjungtani berada di Kecamatan Prambon Kabupaten Nganjuk. Desa tersebut terkenal karena banyak pondok pesantren yang didirikan di sana namun masib banyak warga nya yang abangan. Fenomena tersebut mulai berubah ketika berdirinya Masjid Baitul Makmur. Artikel ini bertujuan untuk membahas pemberdayaan Masjid Baitul Makmur dalam Kehidupan sosial-agama masyarakat desa Tanjungtani. Penelitian ini termasuk penelitian kualitatif dengan menggunakan pendekatan Historis dan sosial. Metode pengumpulan data menggunakan teknik wawancara, observasi, dan studi pustaka. Teori fungsional milik Tallcot Parsons digunakan peneliti sebagai alat analisis data. Hasil dari penelitian ini menunjuk.kan bahwa pemberdayaan masjid sangat penting dalam kehidupan sosial dan dapat membantu mengoptimalkan fungsi dan peran dari Masjid terhadap kebutuban masyarakat.

Kata kunci: Masjid, Pemberdayaan, dan Fungsi

\section{A. PENDAHULUAN}

Indonesia adalah negara yang berlandaskan Pancasila. Agama yang resmi diakui di Indonesia ada enam, yaitu Islam, Protestan, Katolik, Hindu, Budha, dan Konghucu. Setiap agama memiliki tempat peribadatan 
masing-masing. Agama Islam di Indonesia memiliki tempat peribadatan yang disebut masjid. Menurut data Badan Pusat Statistik (BPS), jumlah umat Islam di Indonesia mencapai angka 87,18 \% dari total seluruh penduduk. Faktor tersebutlah yang menjadikan banyaknya jumlah Masjid di Indonesia.

Masjid di Indonesia sudah menyebar ke pelosok-pelosok daerah di Indonesia. Tidak hanya di lingkungan pedesaan atau perumahan warga, masjid sekarang telah berdiri di tempat wisata, taman bermain, dan pusat perbelanjaan. Mantan Wakil Presiden Indonesia sekaligus Ketua Umum Dewan Masjid Indonesia (DMI), Jusuf Kalla, menyatakan bahwa tren masjid di pusat perbelanjaan merupakan kemajuan yang sangat membanggakan karena memudahkan kaum Muslim untuk menjalankan ibadah sholat lima waktu (www.inews.id, 2020).

Masjid memang memiliki peran yang vital bagi perkembangan dan kemajuan umat Islam. Sejak zaman Nabi Muhammad, zaman Khulafaur Rasyidin, dan zaman kerajaan (Dinasti) Islam, Masjid tidak hanya sebagai tempat peribadatan tapi juga sebagai tonggak perkembangan peradaban Islam. Pada era modern seperti sekarang, beberapa masjid di Indonesia mengalami penurunan atau penyempitan fungsi dan peran sehingga digunakan hanya sebatas untuk kegiatan ibadah mahdhah (Syakirin, 2018). Hal itu sangatlah berbanding jauh pada zaman kejayaan Islam. Fenomena tersebut memang terjadi di beberapa wilayah Indonesia, akan tetapi masjid tetap menjadi sebuah instrumen pemberdayaan umat yang memiliki peran strategis dalam upaya peningkatan kualitas dan dapat menyatukan masyarakat (Jannah, 2016).

Berangkat dari uraian diatas, peneliti akan menguraikan lebih jauh tentang fenomena pemberdayaan Masjid yang ada di desa Tanjungtani, Kecamatan Prambon, Kabupaten Nganjuk, Jawa Timur. Peneliti lebih menfokuskan kepada keterkaitan pemberdayaan masjid dengan kehidupan sosialagama masyarakat di desa Tanjungtani. Artikel ini berupaya memberikan deskiripsi tentang salah satu fenomena pemberdayaan masjid di era modern.

\section{B. METODE PENELITIAN}

Penelitian ini dilakukan di desa Tanjungtani, Kecamatan Prambon, Kabupaten Nganjuk, Jawa timur pada bulan Agustus 2020. Objek yang dijadikan penelitian adalah Masjid Baitul Makmur dan masyarakat desa Tanjungtani. Jenis penelitian ini adalah penelitian empiris (Field Research). Penelitian ini termasuk penelitian kualitatif dengan menggunakan pendekatan Historis-Sosiologis. Pendekatan Historis (sejarah) digunakan untuk mengungkap aspek kesejarahan masjid sedangkan pendekatan Sosiologis digunakan untuk mengungkap aspek-aspek sosial. Dalam tahap pengumpulan data, peneliti melakukan wawancara, observasi, studi pustaka. Peneliti melakukan wawancara dengan masyarakat di desa Tanjungtani dan dengan pengurus Takmir Masjid Baitul Makmur dengan menggunakan model wawancara bebas terpimpin dan dengan teknik selected informan. Peneliti melakukan observasi langsung ke Masjid Baitul Makmur dan kondisi masyarakat desa Tanjungtani. Peneliti juga mencari karya-karya ilmiah yang berkaitan dengan pemberdayaan masjid.

Analisis data dilakukan dengan cara mengumpulkan seluruh data wawancara dan studi pustaka. Setelah itu mereduksi data tersebut untuk diklasifikasikan dan dipilih data yang memberikan informasi tentang pemberdayaan Masjid Baitul Makmur dan kehidupan sosial-agama masyarakat desa Tanjungtani. Peneliti juga menggunakan teori fungsional milik Tallcot Parsons sebagai perangkat analisis data. Setelah seluruh data sudah lengkap dan memadai, langkah terakhir adalah pengambilan kesimpulan. 


\section{HASIL DANPEMBAHASAN}

\section{Masjid dan Sejarah Awal Mulanya}

Masjid umumnya dikenal sebagai tempat ibadah yang digunakan oleh umat Islam. Masjid berasal dari kata bahasa Arab Sajada-Yasjudu-sujudan. Dalam Kamus Al-Munawwir kata tersebut yang memiliki arti membungkuk dengan khidmat (Munawwir, 1997). Dari akar kata tersebut, terbentuklah kata "Masjid" yang merupakan Isim Makan (kata dalam bahasa Arab yang menunjukkan tempat) yang berarti tempat untuk sujud. Sujud adalah salah satu rukun shalat, maka Isim Makan, kata benda yang menunjukkan tempat untuk shalat pun diambil dari kata sujud, yang kemudian menjadi kata masjid (Putra \& Rumondor, 2019). Kata "Masjid" dalam Al-Qur'an disebutkan sebanyak 28 kali. Sedangkan kata "sujud" dalam Al-Qur'an digunakan dalam beberapa makna yaitu untuk penghormatan dan pengakuan atas kelebihan pihak lain, menyadari kesalahan dan mengakui kebenaran yang disampaikan oleh pihak lain, dan menyesuaikan diri dengan ketentuan-ketentuan Allah yang ada di alam raya ini (sunnatullah) (Rifa'i, 2016).

Masjid yang pertama kali didirikan adalah Masjid Quba. Masjid tersebut dibangun bersamaan dengan peristiwa hijrah Nabi Muhammad SAW ke Madinah. Rasulullah SAW tiba di Quba pada hari Senin tanggal 8 Rabi'ul Awwal tahun ke-14 Nubuwwah atau tahun pertama Hijriyah, bertepatan tanggal 23 September 662 M, dia membangun masjid yang pertama yang disebut Masjid Quba (Kurniawan, Syamsul. 2014). Masjid Quba dibangun dengan konsep dan desain yang sederhana dengan bahan-bahan berupa pelepah-pelepah dan daun kurma serta batu-batu bata (Putra \& Rumondor, 2019). Masjid yang dibangun kedua adalah Masjid Nabawi. Masjid Nabawi terletak di Madinah dan pembangunannya tidak berselang lama dari Masjid Quba. Rasulullah Saw bersama para sahabat membangun Masjid Nabawi pada bulan Rabiul Awal di awal-awal hijrahnya ke Madinah. Pada saat itu panjang Masjid Nabawi adalah 70 hasta dan lebarnya 60 hasta atau panjangnya $35 \mathrm{~m}$ dan lebar $30 \mathrm{~m}$ (Kurniawan, 2014). Pada waktu itu Masjid Nabawi sangatlah sederhana, berbeda dengan Masjid Nabawi yang sekarang.

Walaupun masjid-masjid zaman dahulu dibangun secara sederhana, konsep pembangunan masjid pada saat itu adalah menjadi tempat pusat aktivitas umat Islam. Masjid pada saat itu juga memainkan peranan yang signifikan dan menjalankan tugas multifungsi dalam pembinaan umat. Fungsi masjid pada zaman Rasulullah dan para sahabat adalah sebagai berikut (Putra \& Rumondor, 2019):

1. Tempat ibadah umatIslam.

2. Tempat Mencari Ilmu.

3. Tempat memberi fatwa.

4. Tempat mengadili perkara.

5. Tempat menyambut tamu, utasan, dan rombongan (kafilah).

6. Tempat melangsungkan pernikahan.

7. Tempat layanan sosial.

8. Tempat latihan perang.

9. Tempat layanan kesehatan.

Fungsi-fungsi di atas menunjukkan bahwa masjid pada zaman dahulu tidak hanya digunakan sebagai tempat ibadah saja, melainkan seimbang antara urusan keagamaan dan urusan duniawi. Masjid pada saat itu menjadi jantung aktivitas umat Islam baik dalam bidang keagamaan, pendidikan, politik, ekonomi, sosial, dan budaya. Hal tersebut menjadikan awal lahirnya peradaban Islam. 


\section{Masjid di Era Modern}

Kondisi era modern dengan zaman Nabi Muhammad dan para sahabat sangatlah berbeda sehingga masjid di zaman sekarang telah mengalami perubahan dan penurunan fungsi. Masjid tetap menjadi tempat penyelengaraan aktivitas ibadah, akan tetapi semakin menyempit. Bahkan beberapa masjid di Indonesia perlu direvitalisasikan fungsinya agar fungsi dakwah, ekonomi, sosial ,dan kesehatan dapat dirasakan oleh masyarakat. Jika pemberdayaan tersebut berhasil dilakukan maka masjid akan kembali menjadi pusat kegiatan umat Islam.

Kesadaran untuk melakukan pemberdayaan masjid di era modern ini mulai berkembang pesat. Hal tersebut dibuktikan dengan banyaknya pihak yang sudah berusaha mengoptimalkan fungsi dan peran masjid. Adapun fungsi masjid disaat sekarang ini sebagai berikut (Putra \& Rumondor, 2019):

1. Sholat Jamaah.

2. Taman Pendidikan Al-Qur'an(TPA).

3. Peringatan hari-hari besarIslam.

4. Perpustakaan Masjid.

5. Pengajian.

6. Tempat diskusi

7. Tempat pengumpul shadaqah, infaq dan zakat.

8. Tempat kegiatan-kegiatan perlombaan seperti kasidah rabanah dan didikan subuh bagi anak-anak.

9. Tempat makan dan minum bersama yang dilaksanakan oleh jamaah Masjid.

Meskipun berjalan pelan, program pemberdayaan masjid harus tetap di dukung dan dikembangkan oleh semua pihak. Masyarakat, lembaga-lembaga Islam dan khususnya pengurus takmir harus terus berusaha menjadikan masjid sebagai sarana dakwah, pengembangan moral dan sosial, pusat pendidikan, pengembangan ekonomi, dan pusat pengembangan politik agar umat Islam dapat merasakan fungsi dan masjid secara optimal.

\section{Pemberdayaan Masjid Baitul Makmur bagi Masyarakat Desa Tanjungtani}

Desa Tanjungtani merupakan salah satu desa yang berada di Kecamatan Prambon Kabupaten Nganjuk. Penamaan Tanjungtani tersebut karena mayoritas warga di sana pada zaman dahulu berprofesi sebagai petani. Sekarang ini desa Tanjungtani terkenal sebagai desa produsen tahu dan tempe. Tanjungtani juga terkenal dengan banyaknya pondok pesantren yang berdiri di sana. Meskipun pondok pesantren juga menjadi ikon dari desa Tanjungtani, masyarakat di sana masih banyak kaum abangan. Menurut Edi Siswoyo, dulu ada beberapa tempat di Tanjungtani yang diberi stigma zona merah karena banyak orang yang suka mabuk, suka tawuran, dan bahkan ngepil (minum narkoba).

Fenomena-fenomena ganjil tersebut perlahan mulai berkurang dengan berdirinya Masjid Karangrejo Baitul Makmur Rahmatullah (lebih dikenal dengan Masjid Baitul Makmur). Masjid tersebut dibangun sekitar pada tahun 1996/1997 dengan tanah wakaf dari beberapa orang yakni bapak Syamsyi, mbah Pat, Haji Lukman, Mbok Jah, ibu Kasmini, dan mbah Juminah. Yang memberikan nama masjid tersebut adalah bapak Syamyi, kiai Nandir, dan kiai Anshori. Awal mula pembangunan masjid didasarkan karena keinginan warga desa Tanjungtani bagian utara yang ingin memiliki tempat untuk belajar mengaji dan sholat berjamaah. Menurut pak Syamsi, proses pembangunan masjid penuh dengan rintangan dan halangan dari beberapa masyarakat dan tokoh agama lainnya karena masyarakat di desa Tanjungtani masih banyak yang abangan dan menganut aliran sapta dharma. Banyak orang juga yang memiliki sifat kolot, keras, dan hanya mementingkan kepentingannya sendiri. 
Bapak Syamsyi dan Kiai Nandir merupakan tokoh utama yang mendirikan Masjid Baitul Makmur, namun hal tersebut tidak lepas dari doa dan dukungan dari para alim ulama yang ada di Nganjuk dan Kediri. Masjid Baitul makmur pada tahun 2000 direnovasi dan diperluas dengan bantuan dana dari ibu Kasmini. Setelah itu barulah dibentuk kepengurusan takmir. Masjid Baitul Makmur diresmikan oleh Bupati Nganjuk pada tanggal 28 Juni 2005.

Hampir 23 tahun Masjid Baitul Makmur berdiri, kegiatan rutin yang ada di sana selain salat berjamaah adalah pengajian kitab, peringatan maulid nabi, khataman Qur'an, liwetan (makan bersamasama), majelis selawat Diba' dan Berjanji. Masjid Baitul Makmur juga memiliki lembaga pendidikan PAUD dan Tama Pendidikan Al-Qur'an (TPA). Keberadaan Masjid Baitul Makmur telah memberikan dampak positif terhadap kehidupan sosial-agama masyarakat desa Tanjungtani. Menurut Edi Siswoyo setelah berdirinya Masjid Baitul Makmur, tingkat kemaksiatan atau kegiatan seperti mabuk, adu ayam, dan kegiatan lainnya yang dilarang oleh agama Islam mulai berkurang secara drastis. Berdasarkan hal tersebut nampak bahwa kegiatan pemberdayaan Masjid di sana berhasil merubah kehiduapan sosial-agama masyarakat desa Tanjungtani.

Pemberdayaan Masjid Baitul Makmur memberikan penjelasan bahwa masjid tidak hanya berfungsi sebagai tempat ibadah saja, tapi masjid juga berfungsi sebagai sarana dakwah, pusat pendidikan, dan kegiatan sosial lainnya. Menurut teori fungsional milik Tallcot Parsons, demi menjaga kestabilan sistem, maka setiap bagian harus menguatkan posisi dan fungsinya masing-masing. Menurutnya ada empat faktor fungsional yang dibutuhkan. Keempat faktor tersebut adalah Adaptation, Goal Attainment, Integration, dan Latency yang dikenal dengan skema A.G.I.L., penjelasan skema tersebut sebagai berikut (Ritzer, 2012):

1. Adaptation adalah sistem yang harus mengatasi kebutuhan situasional yang datang dari luar. Adanya keharusan untuk menyesuaikan diri dengan lingkungan.

2. Goal Attaiment (pencapaian tujuan) adalah keharusan sistem untuk mendefinisikan dan mencapai tujuan-tujuan utamanya.

3. Integration adalah suatu sistem yang harus mengatur antar hubungan bagian-bagian komponennya.

4. Latency (Pemeliharaan pola) adalah keharusan sistem untuk melengkapi, memelihara, dan memperbaharui individu dan pola-pola budaya yang menciptakan dan mempertahankan motivasi tersebut.

Penerapan skema AGIL milik Parsons dapat menjelaskan fenomena pemberdayaan Masjid Baitul Makmur. Pertama dalam skema Adaptation atau adaptasi, dimana adanya tokoh-tokoh yang menjadi pencetus berdirinya masjid dan adanya pihak-pihak pendukung dan donatur yang membantu menyelesaikan berbagai masalah yang ada. Kedua, Goal Attainment atau pencapaian tujuan, dimana adanya kepengurusan takmir yang memiliki program kegiatan atau program kerja yang jelas. Ketiga, Integration atau integrasi, di mana di dalamnya terdapat penyatuan unsur-unsur yang berbeda yang menghasilkan suatu pola dan memiliki keserasian fungsi, sehingga adanya kerja sama atau kolaborasi antara pihak masyarakat, pengurus takmir Masjid Baitul Makmur, dan perangkat desa Tanjungtani. Keempat, Latency atau pemeliharaan pola, hal ini berkaitan dengan adanya kegiatan-kegiatan pemberdayaan untuk generasi muda agar terus meneruskan kegiatan-kegiatan yang sudah berjalan. 


\section{KESIMPULAN}

Masjid merupakan tempat peribadatan umat Islam. Masjid berasal dari bahasa Arab yang memiliki arti membungkuk dengan khidmat. Masjid pertama yang dibangun adalah Masjid Quba ketika nabi Muhammad menjalankan hijrah ke Madinah. Masjid pada zaman dahulu dibangun dengan bahan dan desain yang sederhana. Masjid pada saat itu memainkan peran yang signifikan dan menjalankan tugas multifungsi dalam pembinaan umat sehingga menjadi pusat aktivitas umat Islam.

Masjid di era modern telah mengalami penurunan dan penyempitan fungsi. Masjid mayoritas hanya digunakan sebatas tempat melaksanakan ibadah. Perlu dilakukan pengoptimalan fungsi dan peran masjid agar masjid bisa diperdayakan untuk kepentingan umat.

Desa Tanjungtani merupakan desa yang berada di Kecamatan Prambon Kabupaten Nganjuk. Walaupun pondok pesantren menjadi ikon desa tersebut, masih banyak sekali warga desa Tanjungtani yang abangan dan menganut sapta dharma. Masyarakat luar desa pun ada yang memberikan stigma zona merah ke beberapa daerah di Tanjungtani karena banyak yang melakukan tindakan menyimpang. Kondisi sosial-keagamaan masyarakat Tanjuntani mulai berubah ketika didirikannya Masjid Baitul Makmur. Kegiatan-kegiatan Pemberdayaan Masjid Baitul Makmur memberikan penjelasan bahwa masjid tidak hanya berfungsi sebagai tempat ibadah saja, tapi masjid juga berfungsi sebagai sarana dakwah, pusat pendidikan, dan kegiatan sosial lainnya. 


\section{DAFTAR PUSTAKA}

inews.id. (2019). Jk: Jumlah Masjid di Indonesia Mengalami Kemajuan. Januari 28. Accessed Agustus 25, 2020. www.inews.id/amp/news/nasional/jk-jumlah-masjid-di-indonesia-mengalamikemajuan-luar-biasa.

Jannah, N. (2016). Revitalisasi Masjid di Era Modern (Studi Terhadap Peranannya di Era Modern). Journal Analytica Islamica, 5(1), 125-148.

Kurniawan, S. (2014). Masjid Dalam Lintasan Sejarah Umat Islam. Khatulistiwa, 4(2), 169-184.

Munawwir, A. W. (1997). Kamus Al-Munawwir. Pustaka Progresif.

Naim, Akhsan dan Hendry Saputra, Kewarganegaraan Suku bangsa, Agama, dan Bahasa Sehari-hari Penduduk Indonesia, (Badan Pusat Statistik Indonesia).

Putra, A., \& Rumondor, P. (2019). Eksistensi Masjid di Era Rasulullah dan Era Millenial. TASAMUH, 17(1), 245-264.

Rifa'i, A. (2016). Revitalisasi Fungsi Masjid dalam Kehidupan Masyarakat Modern. Universum : Jurnal KeIslaman Dan Kebudayaan, 10(2), 155-163.

Ritzer, G. (2012). Teori Sosiologi-Dari Sosiologi Klasik Sampai Perkembangan Terakhir Postmodern. Pustaka Pelajar.

Syakirin. (2018). Peran Masjid dalam Mempersatukan Umat Islam: Studi Kasus Masjid Al- Fattah, Pucangan, Kartasura. Al-Balagh : Jurnal Dakwah Dan Komunikasi, 3(1), 127-148.

Wawancara dengan Pak Syamsi selaku pendiri Masjid Baitul Makmur pada tanggal 24 Agustus 2020. Wawancara dengan Pak Sukardi selaku ketua Takmir Masjid Baitul Makmur pada tanggal 24 Agustus 2020.

Wawancara dengan Edi Siswoyo selaku warga desa Tanjungtani pada tanggal 23 Agustus 2020. 